\title{
Examination of the apricot variety use and the factors affecting variety use in the Gönc production area
}

\author{
D. Nagyné Demeter. ${ }^{1}$, Nyéki, J. ${ }^{2}$, Soltész, M. ${ }^{3}$ \& Szabó, Z. ${ }^{2}$ \\ ${ }^{1}$ Károly Róbert College, Faculty of Natural Resources Management and Rural Development, Institute of \\ Agroinformatics and Rural, Mátrai str.36 Gyöngyös, H-3200, Hungary demeterd@ karolyrobert.hu \\ ${ }^{2}$ Institute for Research and Development, University of Debrecen, Centre of Agricultural and Applied Economic \\ Sciences, Debrecen, Hungary \\ ${ }^{3}$ Kecskemét College, Horticultural Faculty, Hungary
}

\begin{abstract}
Summary: Hungary is a traditional fruit growing country for ages. As fruit sector has a very high hand work request and value added, it has an important role to decrease the elimination of unemployment and the lack of income in the disadvantage rural areas. The study was made in the year of 2009, the studied population consisted of the members of the fruit-grower marketing organization (Gyümölcsért Ltd.), that organizes growing and sales of stone fruits in Hungary. The studied area of this Ltd is in North Hungary. The growers, who filled the questionnaire, were selected random simple sample. Two data collection were used during our research work: primer and secondary data collection. The resources of the primer data-collection were the questionnaires of our empirical survey that have been completed by the relevant information from informal interviews with farmers (who previously filled the questionnaires in). We introduced and analysed the local (county level) and the wider (region level) farming conditions by the secondary data. By the composition of the questions both qualitative and quantitative methods have been used. This current study intends to represent one part of this comprehensive research. We wish to briefly introduce mainly the research results concerning variety use.
\end{abstract}

Key words: characteristics of the apricot plantations, questionnaire survey, apricot variety use

\section{Introduction}

During our research, we intended to explore the characteristics of the apricot plantations of the Gönc production area, the knowledge and practice of farmers concerning variety use, their future changes and its specific reasons. Besides this, our aim was to gather the qualitative and quantitative information necessary for the development of consultancy and the research guidelines. Therefore, the basic objective of the study is to put together a comprehensive situation report that supports the identification and reinterpretation of the problems in the variety use in this production area, as well as the solutions to these problems. It is important to emphasise that this current examination is a "situation report", therefore, it cannot describe the temporal changes of the explored phenomena. If we wanted to know these changes, this research should be frequently repeated at given intervals, while continuously actualising the structure of the questionnaire.

\section{Materials and methods}

We performed our own research by a - in the social research activities common-used - questionnaire survey. The latter method has many advantages: it is relative fast and suitable for the descriptive characterisation of large populations and we can easily have a secondary analysis from their data (Huzsvai, 2004).

We used frequency test among descriptive statistics methods, within that the relative and cumulative distribution of variables of a given problem were evaluated and represented. In case of multiple answers the analysis was made by frequency and cross tables upon the previously defined multiple answer groups and sets (Babbie, 2001).

The study was made in the year of 2009, the studied population consisted of the members of the fruit-grower marketing organization (Gyümölcsért Ltd.), that organizes growing and sales of stone fruits in Hungary. The studied area of this Ltd is in North Hungary. The growers, who filled the questionnaire, were selected random simple sample. Two data collection were used during our research work: primer and secondary data collection. The resources of the primer data-collection were the questionnaires of our empirical survey that have been completed by the relevant information from informal interviews with farmers (who previously filled the questionnaires in). We introduced and analysed the local (county level) and the wider (region level) farming conditions by the secondary data. By the composition of the questions both qualitative and quantitative methods have been used. The number of filled out and evaluated questionnaires was 35 . These were the 34 percent of total 
members of the fruit-grower marketing organization (Gyümölcsért Ltd.). So the results of research are valid.

The Gönc production area is the sample area of examination. The quantity of apricot produced in the examined sample area is significant even on the national level. Based on the data of the Agricultural Register (ÁMÖ), $22.2 \%$ of the net area of the Hungarian apricot plantations is constituted by the Gönc production area that is located in BorsodAbaúj-Zemplén County. The plot structure of the plantations is the most concentrated in this apricot production area (a bit more than $73 \%$ of the 1276.88 hectares of apricot plantations are distributed on 10 ha or larger plots). Besides this, the average age of the plantations is also the most favourable (as regards the territorial proportions, the most plantations took place in this area after 2000) and more than half of the apricot yield of 2005 was harvested in Borsod-Abaúj-Zemplén county (Of the 25655 tons total yield, 13289 tons were harvested in Borsod-Abaúj-Zemplén county that includes the production area.)

Therefore, this production area has a high importance in the Hungarian apricot production, this is why the survey and evaluation of the variety use that basically determines the success of production could serve as a guideline even on the national level, mainly in the issues of variety use, variety switch and the acquisition and use of information about varieties. The issues of variety selection strongly depend on the production site endowments of each production area, therefore, research results often describe the characteristics of the given sample area. Nevertheless, in cases when we examined the role of human capital, the results could serve as a guideline even on the national level. In order to be able to fully support these issues, similar survey of the other production areas and the comparison of results per production area are also needed.

\section{Results and discussion}

In part " $\mathrm{k}$ " of the questionnaire, we asked the farmers about the species and variety composition of the plantations managed by them, whereas we also inquired about the factors affecting apricot variety use and the source of information about variety use, as well as the quantity and quality of the information acquired by them.

Besides apricot, there are also other stone-fruits in the plantations managed by the respondents. As a matter of course, the dominant species is apricot, with regard to the sample area (only five interviewees did not deal with apricot production). As for its territorial proportions, apricot was followed by sour cherry, apple, pear, cherry and peach.

The average size of plantations is favourable (Figure 1). Considering that the majority of farms deal with fruit

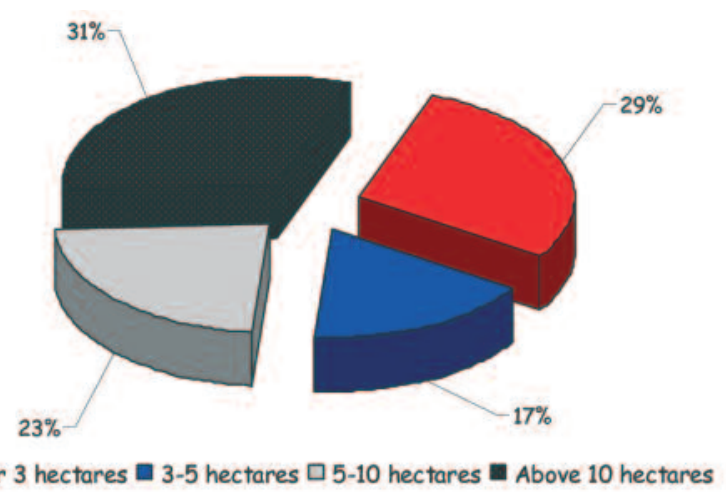

prevails, which is rather noteworthy.

We found a correlation between the form of farming and the size of plantations $\left(\mathrm{p}=0.025, \mathrm{p}^{\prime \prime} 0.05\right)$. There is a tendency of plantations under 3 hectares in the group of primary producers and the proportion of estates above 10 ha increasingly grows depending of the form of farming.

One of the key questions of variety use is how much farmers can satisfy Hungarian and international needs both from the aspect of quantity and quality. We tried to make them provide information about this issue by asking indirect questions. Slightly more than half of the respondents use 4-6 varieties, followed by those who use 1-3 varieties. The proportion of interviewees using seven or more apricot varieties is the lowest. These answering ratios are similar to the listing of varieties and their indicated territorial proportions within the plantation. Altogether, 26 varieties are grown in the plantations of the interviewed producers (the 30 farms dealing with apricot production use 26 varieties altogether). As regards the frequency of answers concerning variety use, "Ceglédi óriás" is ranked first, followed by "Gönci magyar kajszi", "Magyar kajszi", "Ceglédi arany" and "Bergeron". Considering that the fresh food market is ruled by larger fruit products, the leading position of the "giant" variety range (26\%, along with "Szegedi mamut" and "Ligeti óriás") is a rather favourable phenomenon in this production area (Figure 2).

The average ratio of each variety within the plantations is exactly the opposite. "Flavorcot" and "Sweetcot", two varieties whose mentioning ratio was otherwise rather low, have the highest average territorial proportions. The reason of this phenomenon is that even though these varieties are used in few plantations, they still represent a large area and it is probable that these two varieties were produced in relatively large plantations in these cases. Apart from these two extreme cases, the average territorial proportion follows the tendency of the mentioning frequencies. If we plot the mentioning frequencies of each apricot variety against the size categories of the plantations, it can be seen that the proportion of the traditional varieties is high in all categories, 


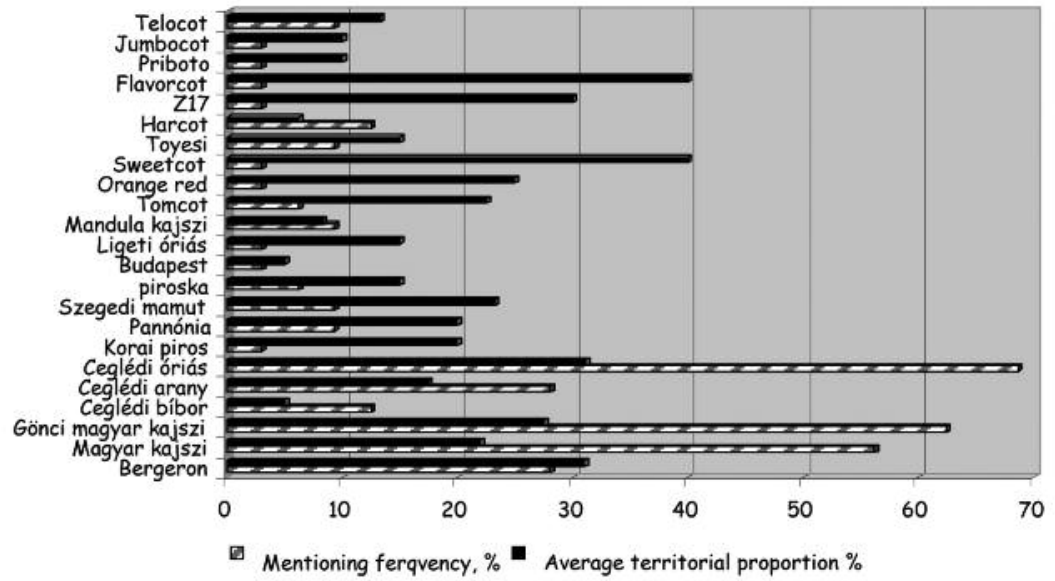

Figure 2. Distribution of used apricot species, and their average yield, in the distribution (\%) of valid answers, 2009

Source: On the basis of empirical research, self-edited.

but the scale of variety use extends with the increase of plantation size and the ratio of newer, more modern varieties increases. Furthermore, it is interesting that the smallest and the biggest size categories contain relatively the same amount of varieties and even their ratios are almost identical. The producers in the "midfield position" use the traditional, tried and tested varieties in more than $80 \%$ of cases.

The examination of the factors affecting farmers' variety use had a high priority in the study. The generally held view that the innovative skills of the farmers are weak and that they rather stick to their production traditions instead of marketfocused farming is not true in this case. It can be seen from the answers that the farmers in the production area mainly prefer competitiveness (Figure 3) in variety use. Nevertheless, there are many occasions when this preference does not prevail in practice. As it will be seen later, the probable reason for this phenomenon is the lack of information and capital, instead of the frequently mentioned problems with mentality. It can be seen in the figure that variety use is mainly affected by sales alternatives, customer needs and production site endowments. The priorities that farmers considered to be the most important ones well reflect the fact that apricot production in the production area is governed by the market.

Based on the results of the correlation analyses, the answers given are proportionate among the educational levels of the respondents, therefore, the educational level does not determine the variety use of farms among the interviewees.

The change in the variety use of the most recent years, as well the lack of these changes are well reflected by the answers we got for the questions about the change of variety use. $48.6 \%$ of respondents have

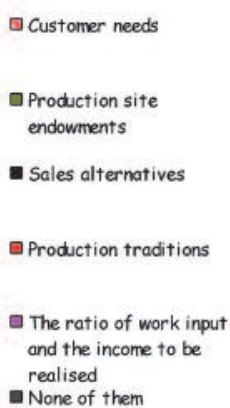
of valid answers, 2009 extended their variety use since the establishment of the plantation. $40 \%$ of them did not change their variety use, whereas, less than $3 \%$ reduced it somewhat. More than half of the respondents started fruit production 10 years ago or before, whereas $37 \%$ of them started it 5-10 years ago. Therefore, the favourable tendency of the extension of variety use mainly took place in the last decade. The main reasons for extension are the improvement of competitiveness, followed by the substitution of aged plantations and the mitigation of unfavourable weather and plant protection phenomena (frost damage) that also cause yield reduction.

We carried out correlation analysis in order to more accurately explore the reasons for the extension of variety use. Based on these correlation analyses, there is no statistical correlation between the ages of the farmers and the factors affecting variety use $(p=0.22)$ neither as a function of the number of workers, the ratio of income from fruit production $(\mathrm{p}=0.28)$, nor the time spent with farming so far $(\mathrm{p}=0.21)$.

The frequency and correlation analyses of the answers given show that farmers consider apricot production to be a market-focused, income oriented activity, despite the fact that it is a part-time activity for most of them. They can assess their degree of production factor supply very well (as if we consider the macroeconomic factors for either the region or the sector, it is really the lack of capital that hinders the competitiveness and the economic development of the region) and they can precisely sense the size and importance of the resources needed for competitive and innovative production ("variety use is mainly affected by sales alternatives, customer needs and production site endowments").

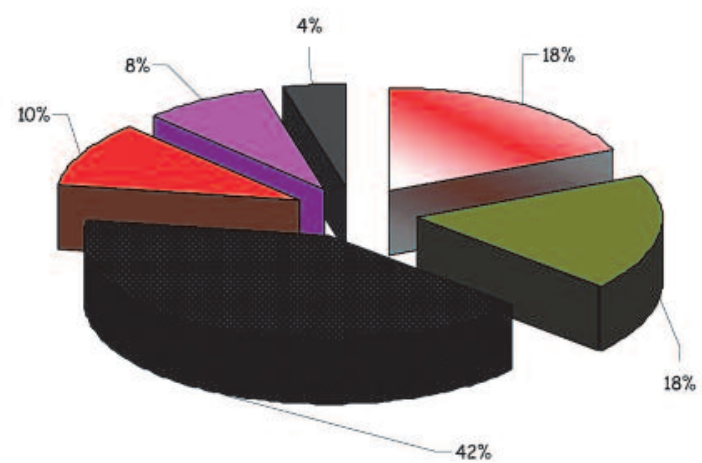

Figure 3. Distribution of determinate of used nectarin species, in the distribution (\%)

Source: On the basis of empirical research, self-edited. 